\title{
The Influence of Online Advertisment on Consumer Attitudes
}

\author{
(Survey on Student Internet Users in The City of Makassar)
}

\author{
Muhammad Aqsa ${ }^{1}$ \\ ${ }^{1}$ Student of Doctoral Program in Management Science, \\ Padjadjaran University, Jalan Dipati Ukur No. 25 \\ Bandung, 40131, Indonesia \\ Email: muhammadaqsa28@yahoo.co.id
}

\author{
M. Risal ${ }^{2}$ \\ ${ }^{2}$ Student of Doctoral Program in Management Science, \\ Padjadjaran University, Jalan Dipati Ukur No. 25 \\ Bandung, 40131, Indonesia \\ Email: mrisal23@gmail.com
}

\begin{abstract}
The rapid development of technology today makes Internet users continues to increase. This is supported by the ease of internet users access the internet either through a PC, laptop, mobile phones, tablets and other media. The increase in Internet users this makes the internet into a proper promotion using online advertisment. Therefore, it is interesting to analyze and examine how the effect of online advertisment on consumer attitudes.

The study was conducted on students of public and private universities in the city of Makassar. The method used was a quantitative analysis using the technique of purposive sampling method with a sample of 340 people. Testing this hypothesis using structural equation modeling (SEM).

The results showed that online advertisment has an influence on consumer attitudes online. Dimensions interactivity of online advertisment provides the highest influence on the attitudes and interests of consumers purchasing online.
\end{abstract}

\section{Keywords; Online Advertisment and Consumer Attitudes}

\section{INTRODUCTION}

The era of globalization has long demanded a paradigm shift in all areas, one of which is the field of marketing. With the high competition in the business world requires a company to be more creative and have a competitive advantage compared with other companies in order to compete in the global business. Reference [1], a new competition is not between what is produced various companies in a factory, but between what is added to the plant results in the form of packaging, services, advertising, consultancy for customers, financing, shipping arrangements, warehousing, and another thing that people think is worth. Competition between products on the market to encourage manufacturers aggressively promote to attract the attention of consumers.

One strategy in marketing is advertisment. Reference [2]; "Informs advertisment function of a product or service or profit companies, as persuasive that persuade consumers to buy certain brands and as a medium to remind consumers of a product or service". Reference [3] ad is: "messages are most persuasive sales are directed to the potential buyers on a particular product or service at a certain cost anyway". Therefore, companies must be able to seize the consumer the impression of the product to be sold and constantly deal with how the product is sold in the market. In order for a product to function to meet the needs and desires of consumers, the existence of such products should be communicated to the consumer in order to be introduced existence.

Advertisment is one component of the promotion mix commonly performed by a company which is a form of promotion that is very instrumental in changing the image, introduce products and the interest of consumers to buy a product. Given the importance of the company's advertisment activities in introducing new products, the company spent heavily on advertisment expenses. Conditions of tight competition makes companies use strategy in creating ads to establish a favorable position in the market [4].

In making the ads need to understand the direct purpose of advertisment is to create the effect of advertisment because communication is a process of communication which in turn will help the sale. Advertisment is the message of a brand, product, or company submitted to the audience through the media [5]. Effective advertisment is not just convey information, but also convey the message that will generate a positive image for consumers. Advertising can be through a variety of media, namely electronic media and print media. In this study will take the electronic media, especially advertisment on the internet.

The development of advertising in today's world are growing rapidly and is supported by rapid technological growth especially internet companies the opportunity to be selective in making advertisment on the Internet to support sales. The use of the internet as a promotional advertisment today is very interesting because it is based on the development of Internet users are very rapid and significant increase every year making the company began to think of using the internet as a medium to promote their products [6]. Through the internet small, medium or large can provide product information, price, purchase terms, ordering and payment, and delivery of goods to customers, prospective 
buyers, and business partners around the world [7]. Internet media serves as a way to reach customers without being limited space and time, and became popular in the world of business today.

Online advertisment is usually found on a website created by a company that aims to promotional activities. Online advertisment should be made attractive to be able to turn away visitors last visited the site and was able to make visitors can revisit those sites, online ads can be a banner (banner), sponsorship, pop-ups, in-stream ads, webcasting, and a link available at the edge, top, bottom, or that suddenly appear on web pages [8]. Therefore it is interesting to look at and investigated further aspects of online advertisment that influence attitudes and consumer interest in making a purchase online. For that in this study adopts an online advertisment model proposed by [9] on in making an online advertisement must have the factor content and communicate. Factor content in online advertisment is how to design the content of the ads may attract the attention of Internet users both in terms of appearance and layout of the ad. While factors communicate contains about how online advertisment can provide a clear and accurate information to consumers about the product being advertised.

\section{THEORETICAL REVIEW}

\section{A. Online Advertisment}

In this study divides into two parts which must be owned by online advertisment are: communicate factor and factor content. Communicate factor is how an online advertisment featuring an information and communication about the product so that users obtain information about existing products in the advertisments, consisting of interactivity and accessibility. Factor content is how the shape, layout and graphics are displayed by online advertisment that attract users to view online ads, consisting of: entertaining, informativeness, irritation, credibility.

\section{a). Communicate factor}

Communicate factor is how an online advertisment featuring an information and communication about the product so that users obtain information about existing products in the advertisments, consisting of interactivity and accessibility.

Interactivity in online advertisment media is the extent of two-way communication that refers to the ability of mutual communication between advertisers and consumers, and the response to the input they receive [10],[11],[12],[13]. Based on the definition of some experts, it can be concluded that the variable interactivity is a two-way communication is done through advertisment via the internet. Indicators used in variable interactivity is: Perceptions of control, related to perceived control over navigation, content and interaction speed .; Perceived response, refer to the online advertising response given .; Personalization, refers to the extent to which consumers feel that the response is appropriate, and relevant.

Accessibility is the ability of users to access information and services provided by online advertisment [14],[15]. The term accessibility is generally related to how users can access the information and content of online advertisment. For example, the text for an image of an advertisment content, download speed and discoverability [14],[15].

\section{b) Content factor}

Factor content is how the shape, layout and graphics are displayed by online advertisment that attract users to view online ads, consisting of: entertaining, informativeness, irritation, credibility.

Entertainment is the ability of advertisment to give pleasure or entertainment to consumers while inserting advertisment information [16], [17],[18],[19],[20]. It deals with how advertisment can influence consumer attitudes to entertainment or an attractive appearance that can make consumers interested in advertisment.

Informativeness an ad ability to supply information to consumers, so as to give a true picture of a product. So that consumers get complete information about existing products [21],[16],[22],[24],[9]. Irritation is a disorder that occurs in online advertising, such as the manipulation of the ad so it leads to fraud, or bad experiences consumers about online advertisment [16],[9],[28].

Irritation is a disorder that occurs in online advertising, such as the manipulation of the ad so it leads to fraud, or bad experiences consumers about online advertising [7],[8].

Credibility in online advertising is how the level of consumer confidence in online advertising that appears, or the extent to which advertising provides information on them can be trusted, impartial, competent, credible and specific [21].

\section{B. Theory of Planned Behavior}

To find out how attitudes affect the interest in online advertisment then used the Theory of Planned Behavior. Theory proposed by Ajzen is widely used by experts to learn how consumer attitudes towards something can affect consumer interest. In this research how consumer attitudes toward advertising can influence consumers to buy online. According to the Theory of Planned Behavior (TPB), the actual behavior of a person to perform a particular action is directly influenced by the behavior intention, which is jointly 
determined also by the attitude, subjective norms, and perceived behavioral control against such behavior. Behavioral intention is a measure of one's willingness to exert effort when performing certain behaviors [50]. Meanwhile, [51] defines the intention is motivational factors that influence the behavior indicated how hard people will try or how much effort expended to perform a behavior.

Attitude is the process of organizing motivation, emotion, perception and long-term cognitive and deals with aspects of the surrounding environment [52]. It deals with how the customer views about online advertisment on the internet related to cognitive and affective factors.

\section{METHODOLOGY}

The research model in this study comprised of online advertisment, consumer attitudes and consumers to buy online. Based on the research model, the research hypotheses are 1) how the perception of Internet users towards online advertisement, 2) the extent of the influence of online advertising on consumer attitudes.

Data collection was performed at public universities student / private in Makassar. Collection using purposive sampling technique by taking a sample of Internet users who are students there Makassar City with an overall sample size of 340 sample.

Descriptive analysis can be done through the preparation of a frequency distribution table and calculation of descriptive statistics such as the average score. Further-more, to facilitate the interpretation of the score, created a frequency distribution table by first categorizing organizational scores into five categories of answers with Sturges criteria as shown in the following table.

TABLE I. SCORES RANGE \& CATEGORY OF EXPORT MARKET ORIENTATION

\begin{tabular}{|c|c|}
\hline Scores Range & Categories \\
\hline $1-1.79$ & Very weak \\
\hline $1.8-2.59$ & Weak \\
\hline $2.6-3.39$ & Fairly Strong \\
\hline $3.4-4.19$ & Strong \\
\hline $4.2-5$ & Very Strong \\
\hline
\end{tabular}

\section{FINDINGS}

To answer the first hypothesis in this research on consumer perceptions of online advertisment, it is descriptive analysis. Summary table, the average value of each dimension of online advertisment. TABLE 2. AVERAGE VALUE DIMENSIONS ONLINE
ADVERTISMENT

\begin{tabular}{|c|c|c|}
\hline Dimension & Scores & Categories \\
\hline Interactivity & 3.74 & Strong \\
\hline Accessibility & 3.59 & Strong \\
\hline Entertainment & 3.67 & Strong \\
\hline Informativeness & 3.66 & Strong \\
\hline
\end{tabular}

\begin{tabular}{|c|c|c|}
\hline Irritation & 2.78 & Fairly \\
\hline Credibility & 3.60 & Strong \\
\hline
\end{tabular}

The test results are descriptive to a statement-statement items contained in each dimension of the questionnaire online advertisment shows that the average value of the resulting pass through the middle value is 3 . Processing and descriptive analysis shows that the majority of Internet users have a high valuation for online advertisment. It shows that in order to establish a good perception into the minds of consumers about the online advertisment in the delivery of online advertisment should pay attention to how the delivery of information can be understood by the consumer, an attractive display ads, and how these ads can entertain consumers.

Delivering a message of good and accurate advertising of a product is very influential on the creation of messages or advertisements useful information for those products which includes in it the quality of the product, price, and where these products can be obtained as well as the use of a good way, so that it becomes a major consideration for consumers to buy.

However, the test results are descriptive in online advertisment especially in dimension irritation showed low yield. It shows that apart from the visual aspect in terms of both appearance online advertisment and information provided, internet users feel that the layout of the online advertisements that have appeared on internet is enough to disturb internet users. For that Internet users expect that in designing the layout design of online advertising on the web need to consider how to position the layout of online advertising that they appear not to disturb the activities of Internet users.

After conducting a series of tests to qualify the data processing models with SEM, then through SPSS Statistics AMOS 20 can be analyzed and calculated as the value of the estimated effect of one variable to another variable and the probability that indicates the level of significance of the effect of one variable to another variable as shown in the figure 1 below this:

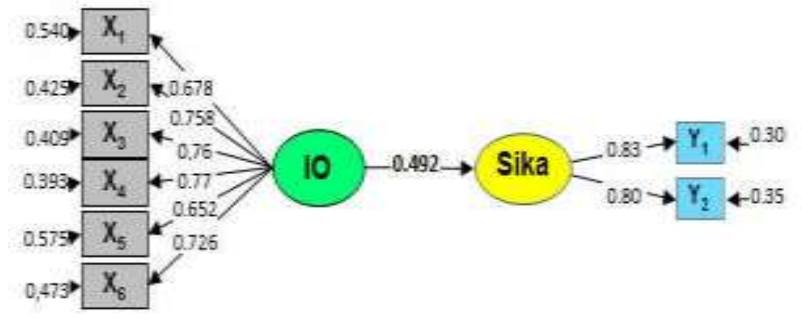

FIGURE $1 \quad$ VARIABLE CAUSALITY TEST

To see the impact of online advertiment on consumer attitudes, as hypothesized in the second hypothesis that online advertisment has positive influence on consumer attitudes. To test this hypothesis used by the Student t-test statistical test results as follows are shown in Table 3 below: 
TABLE I. ONLINE ADVERTISMENT IMPACT ON CONSUMER ATTITUDES

\begin{tabular}{|c|c|c|c|c|c|}
\hline Hypothesis & Influence & $\begin{array}{c}\text { Standart } \\
\text { Error }\end{array}$ & $t$ & $\begin{array}{c}\mathrm{t}- \\
\text { table }\end{array}$ & Decision \\
\hline $\begin{array}{l}\text { Ho:y1.1 } \leq 0 \\
\text { H1:y1.1 }>0\end{array}$ & 0.492 & 0.065 & 11.83 & 1.96 & $\begin{array}{c}\text { Reject Null } \\
\text { Hypothesis }\end{array}$ \\
\hline
\end{tabular}

Based on the obtained values of the test Statistically t-test of 11.834 is greater than the value of the t test table by 1.96 at $5 \%$ error rate can be concluded that the null hypothesis is rejected. This means that online advertisment significantly influence consumer attitudes. Influence of online advertisment on consumer attitude is positive medium ( $49.2 \%$ ). This means that every increase of one standard deviation of online advertisment will increase the value of consumer attitudes, a large effect is moderate and the remaining $50.8 \%$ of consumer attitudes are influenced by variables outside of online advertisment.

Delivering a message of good and accurate advertisment of a product is very influential on the creation of messages or advertisements useful information for those products which includes in it the quality of the product, price, and where these products can be obtained as well as the use of a good way, so that it becomes a major consideration for consumers to buy.

Based on these results indicate that consumer attitudes toward advertisment online form various kinds of feelings and judgments as a result of ad views, feelings and judgments affect consumer attitudes toward advertisment and beliefs related to online advertisment. It also illustrates that consumer behavior before acting, consumers often develop a desire to behave based on the possibility of an attitude or action taken.

Online advertisment is good in consumer perception can form a good attitude toward the ad. Online advertisment to influence consumer attitudes when forming various feelings and considerations as a result of exposure to advertisment. Feelings and considerations in turn affect consumer attitudes toward advertisment. Good advertisment messages to contribute to consumer attitudes. Means that the quality of advertisment messages delivered to consumers will arise a strong consumer confidence against the existence of these products and the value of the product will be higher so as to realize consumer attitudes.

Theory of advertisment and its influence on the attitude put forward by [53] also stated that the basic model relationships can influence the attitudes ads when consumers form a variety of feelings (influence) and consideration (cognition) as a result of exposure to advertisment. Feelings and considerations in turn affect consumer attitudes toward advertising and confidence in the brand acquired from exposure to advertisment. This shows that online advertisment can influence consumer attitudes. For it to be able to attract and form a positive perception of consumer attitudes toward advertisment online advertisment should be packed in an interesting and entertaining. Because according to a study of the first things seen by online consumers of advertisment is the advertisment display is attractive or not. In addition, how the information provided can give input and an overview of the products offered.

Once the consumers' perception of online advertisment is good, then consumer attitudes toward advertisment will also be good. This is in line with research conducted by [53], in a study which studied how consumer attitudes towards online advertisment. In his research used content factor, a factor of emotional feelings and brand factors on the effectiveness of advertisment. The results showed that the influence of advertisment content associated with the content of online advertisment makes interested users, the results also showed that attitudes are positive towards online advertisment leads to a positive attitude of consumers towards online advertisment.

Other studies conducted by [54], they examined how online ads affect consumer attitudes, studies conducted in the country of India. They find that their likes of advertisements, their confidence in online advertisment and entertainment that they find interesting can make consumer attitudes toward online advertisment to be good. Reference [55] conducted a study on how online advertisment affects consumer attitudes towards online advertisment. In his research using variables brand name, content, and consumer purchasing decisions. The results found that the factor content or the content of the online advertisment affect consumer attitudes toward advertisment is strong and positive, because the update information to provide input to consumers and forming attitudes towards online advertisment. Several other studies on the influence of a strong and positive attitude towards advertisment online [56].

\section{CONCLUSIONS}

Based on the results of research conducted found that, online advertisment appearing during this in internet got good perception of internet users. It deals with how the look and design of advertisment can form a good perception of online advertisment. However, the placement of online advertisment layout deserves attention because Internet users get annoyed with the layout of the online advertisements on the internet.

Online advertisment has a significant influence on consumer attitudes. Ads oline designed both visually appealing or display ads and advertisment information messages that include product quality, price and other information to form various kinds of feelings and judgments as a result of ad views, feelings and judgments affect consumer attitudes toward advertisment and trust associated with online advertisment. It also illustrates that consumer behavior before acting, consumers often develop a desire to behave based on the possibility of an attitude or action taken.

\section{Acknowledgment}

The author wishes to acknowledge all the contributors for developing and maintaining this article, especially to promotor doctoral program in management science Padjadjaran 
University, Prof. Dr. Hj. Dwi Kartini, SE, Spec.lic. And copromotors Prof. Dr. Faisal Afiff, SE, Spec.Lic, and Dr. R. Arief Helmi, SE, M.Si.

\section{References}

[1] Kotler, Philips, "Marketing Strategy and Management: Analisys, Planning, Implementation and Control", 8th ed. Englewood Cliffs, N.J: Prentice Hall International. Inc; 2012.

[2] Joonghwa Lee, M.A and Mira Lee, Ph.D, "Factors Influencing the Intention to Watch Online Video Advertising", Cyberpsychology, Behavior, and Social Networking Volume 14, Number 10; 2007.

[3] Malthouse, Edward C. Calder, Bobby J. Tamhane, "The Effects Of Media Context Experiences On Advertising Effectiveness", Journal of Advertising.Fall 2007; 36; 3; ProQuest pg. 7.

[4] Stoner, J.A.F. R.E. Freeman, Management in Marketing and Strategy Planning.6th.ed. Englewood Cliffs, N.J: Prentice Hall International. Inc; 2004.

[5] Richards, Jef Curran and Catharine $M$, Oracles on "advertising Searching for a definition", Journal of Advertising 31, 2; ProQuest pg. $63 ; 2002$.

[6] Stern, B. L, Krugman, D. M, \& Resnik, "A Magazine Advertising: An Analysis of Its Information Content-Do ads inform or persuade?", Journal of Advertising Research, 21 (2): 39-44, 2007.

[7] Stefan Schwarzkopf, "What Was Advertising? The Invention, Rise, Demise, and Disappearance of Advertising Concepts in Nineteenth - and Twentieth-Century Europe and America", Business and economic online, vol 7, 2009

[8] Malthouse, Edward C. Calder, Bobby J. Tamhane, "The Effects Of Media Context Experiences On Advertising Effectiveness", Journal of Advertising Fall 2007; 36, 3; ProQuest pg. 7.

[9] Nasser Yazdani, "Designing and Validating a Systematic Model of EAdvertising", International Journal of Marketing Studies Vol. 4, No. 2; April 2012

[10] Stern, B. L., Krugman, D. M., \& Resnik, "Magazine Advertising: An Analysis of Its Information Content - Do ads inform or persuade?", Journal of Advertising Research, 21 (2): 39-44.

[11] Sabatini and Joanna, "Reebok makes its move into online marketing", Adweek; Jan 3 ; ProQuest Research Library pg. 28.

[12] Justin P. Johnson, "Targeted Advertising and Advertising Avoidance", RAND Journal of Economics Vol.44, No.1 pp.128-144, 2013.

[13] Stefan Schwarzkopf, "What Was Advertising? The Invention, Rise, Demise,and Disappearance of Advertising Concepts in Nineteenth- and Twentieth-Century Europe and America", Business and economic online, vol 7, 2009

[14] Zain-Ul-Abideen and Salman Saleem, "Effective advertising and its influence on consumer buying behavior", European Journal of Business and Management ISSN 2222-1905 (Paper) ISSN 2222-2839 Vol 3 , No.3.

[15] Wathen, C Nadine;Burkell, Jacquelyn, "Believe it or not: Factors influencing credibility on the Web", Journal of the American Society for Information Science and Technology; Jan 15, 2002; 53, 2; ProQuest pg. 134.
[16] Fotini Patsioura, Maro Vlachopoulou and Vicky Manthou, "A New Advertising Effectiveness Model for Corporate Advertising Web Sites", Benchmarking: An International Journal Vol. 16 No.3 pp.372-386.

[17] Gresi Sanje and Isil Senol, "The Importance of Online Behaviora Advertising for Online Retailers", International Journal of Business and Social Science Vol.3 No.18, 2012.

[18] Hyunjae Yu, Hye-Jin Paek and Bumjun Bae, "Cross-cultural comparison of interactivity and advertising appeals on antismoking web sites in the United States and South Korea", Internet Research Vol. 18 No. 5, 2008 pp. 454-476.

[19] Isbond, Peter Paul J, "Consumer Behavior and Marketing Strategy", McGraw Hill International, London.

[20] James Mathew, Peter M. Ogedebe and Segun M. Ogedebe, "Influence of Web Advertising on Consumer Behaviour in Maiduguri Metropolis, Nigeria", Asian Journal Social of Social Sciences \& Humanities.

[21] Jiang, Pingjun and Rosenbloom, Bert, "Customer intention to return online European Journal of Marketing", 2005; 39, 1/2; ABI/INFORM Complete pg. 150.

[22] Kelman, H. C, "Processes of Opinion Change", Public Opinion Quarterly, 25, 57-78.

[23] Mackie, D. M, "Systematic and Nonsystematic Processing of Majority and Minority Persuasive Communications", Journal of Personalityand Social Psychology, 53, 41-52.

[24] Aaker, David A, "Causes of Irritation in Advertising", Journal of Marketing (pre-1986); Spring 1985; 49, 000002, ABI/INFORM Complete pg. 47; 1986.

[25] Pollay, R. W, "Measuring der Cultural Values Manifest in Advertising", Current Issues and Research in Advertising, 6: 71-92.

[26] Stern, B. L., Krugman, D. M., \& Resnik, "Magazine Advertising: An Analysis of Its Information Content - Do ads inform or persuade?", Journal of Advertising Research, 21 (2): 39-44.

[27] Sabatini and Joanna, "Reebok makes its move into online marketing", Adweek; Jan 3 ; ProQuest Research Library pg. 28.

[28] Stewart, David W. McGann, Anthony F, "Speculations on the Future of Advertising Research Journal of Advertising", Sep 1992; 21, 3. ProQuest pg. 1.

[29] Stefan Schwarzkopf, "What Was Advertising? The Invention, Rise, Demise,and Disappearance of Advertising Concepts in Nineteenth- and Twentieth-Century Europe and America", Business and economic online, vol 7, 2009.

[30] Terry, George R, "Consumer Behavior and Desainer in Taking Decision", Six Edition, Prentice Hall, New jersey

[31] Zain-Ul-Abideen and Salman Saleem, "Effective advertising and its influence on consumer buying behavior", European Journal of Business and Management ISSN 2222-1905 (Paper) ISSN 2222-2839 Vol 3, No.3

[32] Ying Wang and Shaojing Sun, "Examining the role of beliefs and attitudes in online advertising a comparison between the USA and Romania", International Marketing Review Vol. 27 No. 1, 2010 pp. 87107.

[33] Wathen, C Nadine;Burkell, Jacquelyn, "Believe it or not: Factors influencing credibility on the Web", Journal of the American Society for 
Information Science and Technology; Jan 15, 2002; 53, 2; ProQuest pg. 134.

[34] Alan D. Smith, "Online accessibility concerns in shaping consumer relationships in the automotive industry", Online Information Review Vol. 33 No. 1, 2009 pp. 77-95.

[35] Assael, Herry, "Consumer Behaviour and Marketing Action", 8thedition, South-Western College Publishing, New York University.

[36] David S. Evans, "The Online Advertising Industry: Economics, Evolution, and Privacy", Journal of Economic Perspectives Volume 23 , Number 3 Pages 37-60.

[37] Bennett, P.D, Marketing and Strategy Marketing Management.New York: The American Marketing Association.

[38] Geoffrey and Lincoln, "A Model of Consumer Response to Advertising Music", Journal of Consumer Marketing 29/1 (2012) 22-24.

[39] Haigood, T. L., and Dacin, P. A, "The Impact of Involvement and Argument Type on the Persuasiveness of Popularity Claims in Advertising", In Proceedings of the American Marketing Association Winter Educators' Conference, Vol. 10. Chicago, IL: American Marketing Association, 19-20.

[40] Henry Maria, "Integrative online shopping model: The mediating role of advertising", ProQuest Dissertations and Theses: The Humanities and Social Sciences Collection.

[41] Hair, Yoseph F. Jr., Rolph E. Anderson, Ronald L. Tatham \& William C. Black, Multivariate Data Analysis with Readings, Fourth Edition, New Jersey Prentince-Hall, Inc.

[42] Corey, Cravens, 2001. Strategy Marketing. 4th ed. Burr Ridge, Illinois: Richard D. Irwin, Inc.

[43] Fotini Patsioura, Maro Vlachopoulou and Eleonara, "A Relationship Marketing Model for Brand Advertising Websites: An Analysis of Consumers' Perceptions", International Journal of Management Vol.28 No.4 Part 1.
[44] Giorgio Brajnik and Silvia Gabrielli, "A Review of Online Advertising Effects on the User Experience", Intl. Journal of Human-Computer Interaction, 26(10), 971-997, 2010.

[45] Jae Jin Park, "Understanding Consumer Intention to Shop Online". A Dissertation presented to the Faculty of the Graduate School University of Missouri - Columbia.

[46] Ajzen, I., The theory of planned behavior, Organizational Behavior and Human Decision Processes, Vol. 50, pp. 179-211; 1991.

[47] Schiffman, Leon G, and Kanuk, Leislie Lazar, Consumer Behavior. Seventh Edition. USA :Prentice-Hall, Inc; 2000

[48] Justin P. Johnson, "Targeted Advertising and Advertising Avoidance", RAND Journal of Economics Vol.44, No.1 pp.128-144, 2013

[49] John Chandler-Pepelnjak, "Modelling Conversions in Online Advertising", The University of Montana.

[50] Pollay, R. W, "Measuring der Cultural Values Manifest in Advertising", Current Issues and Research in Advertising, 6: 71-92.

[51] Stefan Schwarzkopf, "What Was Advertising? The Invention, Rise, Demise,and Disappearance of Advertising Concepts in Nineteenth- and Twentieth-Century Europe and America", Business and economic online, vol 7, 2009.

[52] Shaffer, Greg;Zettelmeyer, Florian. Advertising in a Distribution Channel.Marketing Science.Fall 2004; 23, 4; ProQuest pg. 619

[53] Wolin, Lori D, Korgaonkar and Pradeep, "Web advertising: Gender differences in beliefs, attitudes and behavior", Internet Research; 13, ProQuest pg. 375.

[54] Sarmad, Z., Bazargan, A., and Hejazi, E, Research Methods in Behavioral Sciences. Tehran, Agah Publications.

[55] Rodgers, Shelly, "The Effects of Sponsor Relevance on Consumer Reactions to Internet", Sponsorship.Journal of Advertising, 32(4), 6876. 